View Point

\title{
Small Volume of Rabies Immunoglobulin (RIG) is Effective for Local Wound Infiltration in Rabies Post-Exposure Prophylaxis whereas Intramuscular RIG is just a Wastage
}

\author{
Omesh Kumar Bharti', David C Anderson'2, Jugal Kishore ${ }^{3}$, Pankaj Katoch ${ }^{4}$, \\ Pururava Sharma $^{5}$

\begin{abstract}
${ }^{1}$ State Epidemiologist, State Institute of Health \& Family Welfare, Kasumpti, Shimla, Himachal Pradesh, India. ${ }^{2}$ Former Professor of Medicine, The University of Manchester and The Chinese University of Hong Kong. ${ }^{3}$ Director Professor \& Head, Department of Community Medicine, VMMC \& SJH, New Delhi, India. ${ }^{4}$ Senior Resident, Department of Microbiology, IGMC Shimla, Himachal Pradesh, India. 5Junior Resident, Department of OBG, DGCN COVAS, Palampur, Himachal Pradesh, India.
\end{abstract} \\ DOI: https://doi.org/10.24321/2349.7181.202112
}

$\begin{array}{lllllll}\mathbf{I} & \mathbf{N} & \mathbf{F} & \mathbf{O}\end{array}$

Corresponding Author:

Omesh Kumar Bharti, State Institute of Health \& Family Welfare, Kasumpti, Shimla, Himachal Pradesh, India.

E-mail Id:

bhartiomesh@yahoo.com

Orcid Id:

https://orcid.org/0000-0001-5178-1503

How to cite this article:

Bharti OK, Anderson DC, Kishore J, Katoch P, Sharma P. Small Volume of Rabies Immunoglobulin (RIG) is Effective for Local Wound Infiltration in Rabies Post-Exposure Prophylaxis whereas Intramuscular RIG is just a Wastage. J Adv Res Med. 2021;8(3):8-12.

Date of Submission: 2021-09-02

Date of Acceptance: 2021-09-27
$\begin{array}{llllllll}\mathbf{A} & \mathbf{B} & \mathbf{S} & \mathbf{T} & \mathbf{R} & \mathbf{A} & \mathbf{C} & \mathbf{T}\end{array}$

Rabies is a zoonosis that is $100 \%$ fatal once symptoms of the disease appear. However, it is almost $100 \%$ preventable if the prophylactic measures with proper wound wash, vaccines and immunoglobulins are taken soon after exposure to the animal bite. A general tendency has been noticed among clinicians all over the world to inject Rabies Immunoglobulins (RIG) intramuscularly, mostly in the gluteal muscle, despite the guidelines that suggest infiltrating it into the wounds. This has resulted in failures of Post Exposure Prophylaxis in many countries leading to the death of patients due to rabies. Here we discuss how giving any amount or even large amount of RIG intramuscularly (IM) is not going to neutralise rabies virus at the wound site especially during the window period, exposing the patients to the risk of rabies, whereas a small volume of RIG injected into the wound(s) is a lifesaving intervention as it neutralises the virus there and then in the wound(s) especially during the initial window period when the exposed person is unprotected, as the response to concurrent vaccination may take 10-14 days after exposure/ bite.

Keywords: Rabies, Rabies Immunoglobulins, Post Exposure Prophylaxis

\section{Introduction}

Rabies causes the death of approximately 59,000 humans and the loss of more than 3.7 million disability-adjusted life years (DALYs) every year. ${ }^{1}$ Most of these cases are found in
Africa and Asia, with nearly $40 \%$ of these cases in children aged $<15$ years. Rabies virus is generally found on dogs and more than $99 \%$ of the cases of rabies in humans are because of dog bites. ${ }^{2}$ Prophylaxis such as rabies vaccine 
and Rabies Immunoglobulin (RIG) injection into the bite wounds, if given to the victim at the right time, can prevent rabies. ${ }^{3,4}$ After inoculation/ bite, the rabies virus seeks to enter a nerve ending and thereafter progresses towards the brain within an immune protected nerve. The risk of rabies is increased in a patient in whom the infection occurs within a week and prior to the development of sufficient post-vaccination antibody levels. There is no viremia and therefore the virus remains on the surface of wound(s). Effective post-exposure prophylaxis (PEP) after being bitten involves; a) flushing of virus from wounds through effective washing with soap and water and applying any disinfectant; b) active immunisation with the vaccine; and c) most importantly, neutralisation of any residual virus within the wound(s) itself with local infiltration of whereas Intramuscular RIG is Just a Wastage.

The short incubation periods in rabies are a known reality especially in children where bites are mostly closer to head and neck due to short stature. After being bitten, even after wound washing, for varying periods of time, some rabies virus may be present at the site of the bite. This requires administering antibodies passively into the wound in order to neutralise the virus. Rabies vaccine takes about 10-14 days to mount an effective immune response achieving a protective titer of nearly $0.5 \mathrm{lU} / \mathrm{ml}$ of serum. This $10-14$ days window period needs to be bridged to protect the patient from rabies. To bridge this window of risk, WHO recommends that passive immunisation with readymade antibodies called Rabies Immunoglobulins (RIG) needs to be done as early as possible after exposure to the rabid animal by injecting RIG into the wound(s) to neutralise the virus in the affected area.

Recently WHO has recommended ${ }^{5}$ only wound infiltration of RIG without IM administration except in rare circumstances where the wound is not available for infiltration e.g. aerosol exposure etc. The Advisory Committee on Immunization Practices of Center for Disease Control and Prevention (CDC ACIP) guidelines have not yet been updated to follow suit $^{6}$ and doctors still continue to give IM RIG for PEP in the USA. ${ }^{7}$ However, new guidelines by National Centre for Disease Control (NCDC), India have endorsed only wound infiltration as per WHO guidelines. ${ }^{8}$ Still some doctors in India ${ }^{9}$ and abroad $^{10}$ prefer giving RIG Intramuscular (IM), in the mistaken belief that it is equally effective and less painful than injecting RIG into the wounds. Neither of these beliefs is true, and this action only results in the failure of PEP. ${ }^{11,12}$ Here we present evidence from one case study that even full calculated volume of RIG based on the weight of the patient, when injected Intramuscularly (IM) did not have neutralising antibodies in the blood of the patient at day 3 and thereby exposed the patient to the risk of rabies. In May 2014, a 24-years-old male had gone to a nearby city, Chandigarh, and was bitten by a stray dog on the right lower leg. The dog was suspected to be rabid and had bitten other people as well. He went to a government anti-rabies clinic and was given a dose of rabies vaccine IM and also a full dose of equine RIG (eRIG) calculated based on his body weight (62 kg) i.e. $8.5 \mathrm{ml}$ into gluteus muscle IM, no wound infiltration was done contrary to guidelines. The patient reported to us at our Anti-Rabies Clinic \& Research Centre, DDU Hospital Shimla, Himachal Pradesh on day 3 for the next dose of vaccine injection. He was anxious to know if he was protected or not. He got his serum sample tested for rabies antibodies by Rapid Fluorescent Focus Inhibition Test (RFFIT) from a reference lab at the National Institute of Mental Health \& Neurosciences (NIMHNS), Bengaluru, India. The report from NIMHANS said that only traces of antibodies were there and no measurable antibodies were present on day 3 even after full IM injection of eRIG to the patient in Chandigarh. Later on, he was given local wound infiltration of eRIG on day 6 when a vial of eRIG could be made available after a long search as RIG was not available in the market. This case study clearly shows that IM injection of full calculated dose of RIG is not going to give protective titers during the window period, thus exposing the patient to the risk of rabies if the rabies virus attaches with the exposed nerve ending within this window period and in that case, no amount of vaccine or RIG can save the patient subsequently as the virus then becomes immune protected within the nerve. Many other studies show the failure to give protective antibody levels in human serum by RIG injected IM. ${ }^{13,14}$ RIG is in limited supply all over the world and only wound infiltration would not only save costs, ${ }^{15,16}$ but also spare up to $60 \%$ of RIG volume for India ${ }^{17}$ and other countries where RIG is not available. ${ }^{18}$

Animal model studies have clearly shown that any amount of RIG given IM is of no use as no effective titers of antibodies (i.e. $\geq 0.5 \mathrm{lU} / \mathrm{ml}$ of serum) are achieved during the unprotected window period of 10-14 days while the vaccine begins to produce an effective endogenous immune response. A four times dose, as prescribed by weight for RIG, did not help rabies antibodies appear in the blood of mice injected IM Human RIG (HRIG) in a study done by China $\mathrm{CDC}$ recently. This clearly shows the importance of local wound infiltration of RIG for severe cases (exposure severity, category III), and its efficacy in providing an immediate supply of antibodies in order to neutralise the virus. ${ }^{19}$ On the other hand, only local wound infiltration of RIG has saved many lives, not only in humans bitten by lab confirmed rabid dogs, ${ }^{20}$ but also of animals bitten by lab confirmed rabid dogs and mongoose where small amounts of eRIG injected into the wound(s) along with vaccination in cows and buffaloes saved their lives. ${ }^{21}$

It is impossible to know the viral load in the wound that needs to be neutralised with local wound injection of RIG. A few studies have demonstrated that the salivary glands of 
rabid dogs contain $10^{2}$ to $10^{4} \mathrm{LD}_{50}$ per gm quantum of the virus. $^{22,23}$ It has also been revealed that RIG as low as 0.025 IU can completely neutralise a dose of $10^{4} \mathrm{FFD}_{50}$ of the virus, whereas, both HRIG and ERIG, in all dilutions, have been found to be effective in completely neutralising a virus dose of $10^{3} \mathrm{FFD}_{50}{ }^{24}$ Theoretically speaking, as $0.5 \mathrm{IU} / \mathrm{mL}(\mathrm{IU} / \mathrm{mL})$ of rabies antibodies in serum has been recommended by WHO as indicative that a vaccinated person has responded to the rabies vaccine ${ }^{25}$ therefore to protect a patient, we need $0.5 \mathrm{IU} / \mathrm{ml}$ of RIG at the wound site to neutralise whatever viral load is inoculated there inside the wound. That means, theoretically, we can dilute $1 \mathrm{ml}$ of eRIG (300 $\mathrm{IU} / \mathrm{ml}$ ) up to 600 times and HRIG (150 IU/ml) up to 300 times for local wound infiltration at the wound site to achieve antibody titers of $0.5 \mathrm{lU} / \mathrm{ml}$ for protection by rabies virus neutralisation. This hypothesis of dilution of eRIG generated enough confidence in our team at Anti Rabies Clinic \& Research Centre, DDU Hospital Shimla, Himachal Pradesh, India to inject a minimum dose of $0.025 \mathrm{ml}$ (7.5IU) of eRIG into the scratches/ wounds of our patients ${ }^{26}$ who had small nail puncture wounds and this small volume of eRIG was enough to kill any amount of virus that could have been present there in the wound as all our patients, some of them bitten by lab confirmed rabid dogs, survived. WHO advocates that to ensure complete infiltration of the affected area, especially in cases of large and multiple wounds, RIG can be diluted with physiological buffered saline, if deemed necessary. The practice of injecting the leftover quantity of the calculated RIG dose IM at a distance from the wound is not recommended now by WHO. ${ }^{27}$ Recently in China, a four years eight months old girl child bitten by a confirmed rabid dog was given wound infiltration of HRIG diluted 15 times and she survived. ${ }^{28}$

While RIG given IM fails to reach blood due to large molecular size of the immunoglobulins and remains deposited in the muscle with the additional risk of serum sickness, swelling, reaction, and anaphylaxis, ${ }^{29}$ administration of local injection of eRIG is associated with negligible reaction. ${ }^{26}$ Injection of the remaining eRIG into the muscle as per previous WHO guidelines used to have a high reaction rate including serum sickness up to $3 \%$ of recipients and anaphylaxis in some of them. Apart from this, additional RIG given IM contributes to lower the immune response to rabies vaccine. ${ }^{30,31}$

Based on our experience of RIGs, it is worth studying the bioavailability of other immunoglobulins given IM like Tetanus immunoglobulin by IM route, Human Gamma-globulin by IM route, Diphtheria antitoxin/ pertussis immune globulin given by IM route, Human Hepatitis B immunoglobulin and other similar other immunoglobulins being given IM by the clinicians to generate enough confidence in the clinical outcomes.

\section{Conclusion and Recommendations}

Any amount of Rabies Immunoglobulin (RIG) i.e HRIG, eRIG, or Rabies Monoclonal Antibodies (RMab) given intramuscular (IM) is not going to protect the patient from rabies in a window period and may expose the patient to the danger of contracting rabies if virus attaches to the nerves during the window period and before protective immune response due to rabies vaccination has been developed.

To protect the patient from rabies, it is essential that clinicians inject the wounds with local infiltration of RIG by covering the entire surface of the wound(s) till the depth so as to neutralise any rabies virus that is present at the surface of the wound(s) to save lives. All wound(s) need to be infiltrated separately, howsoever small abrasions they may be. Broken skin or abrasions can be assessed by "Spirit Test". If there is doubt about the nature and classification of wounds, then a spirit swab is applied to the affected area and if there is a tingling/ burning sensation, it means that skin is broken ${ }^{32}$ and would require local RIG infiltration and vaccination after a thorough wound wash and application of antiseptics. Also, a large amount of RIG at the wound site is not required and covering the surface of wound(s) till depth is enough for protection, practically mean volume of RIG required for injecting wounds is less ${ }^{26}$ than the total calculated volume based on body weight and the remaining volume of RIG in the opened vial can be used to infiltrate the wounds of the remaining patients. ${ }^{26} \mathrm{~A}$ small volume of RIG injected locally into the wound site(s), which is the only place where it is needed, will suffice to kill a large load of virus inoculum and therein lies the importance of confining the infiltration of RIG products to the wound(s) only rather than improvidently injecting them IM.

\section{Conflict of Interest: None}

\section{References}

1. Hampson K, Coudeville L, Lembo T, Sambo M, Kieffer A, Attlan M, Barrat J, Blanton JD, Briggs DJ, Cleaveland S, Costa P, Freuling CM, Hiby E, Knopf L, Leanes F, Meslin FX, Metlin T, Miranda ME, Müller T, Nel LH, Recuenco S, Rupprecht CE, Schumacher C, Taylor L, Vigilato MA, Zinsstag J, Dushoff J; Global Alliance for Rabies Control Partners for Rabies Prevention. Estimating the global burden of endemic canine rabies. PLoS Negl Trop Dis. 2015;9(4):e0003709. [PubMed] [Google Scholar]

2. Fooks $A R$, Cliquet $F$, Finke $S$, Freuling $C$, Hemachudha T, Mani RS, Muller T, Nadin-Davis S, Picard-Meyer E, Wilde H, Banyard AC. Rabies. Nat Rev Dis Primers. 2017 Nov 30;3:17091. [PubMed]

3. Anderson DC. WHO guidelines dealing with immunoglobulin use impede rabies prevention. Asian Biomed. 2007;1(1):103-7. [Google Scholar] 
4. Bharti OK, Madhusudana SN, Gaunta PL, Belludi AY. Local infiltration of rabies immunoglobulins without systemic intramuscular administration: an alternative cost effective approach for passive immunization against rabies. Hum Vaccin Immunother. 2016;12(3):837-42. [PubMed] [Google Scholar]

5. World Health Organization [Internet]. WHO Expert Consultation on Rabies: WHO TRS No. 1012. Third report; 2018 [cited 2019 Sep 4]. Available from: https://apps.who.int/iris/bitstream/hand le/10665/272364/9789241210218-eng.pdf?ua=1\%20 Accessed\%20on\%20September\%2023,\%202019\%20

6. Bookstaver PB, Akpunonu P, Nguyen HB, Swan JT, Howington GT. Administration of rabies immunoglobulin: improving evidence-based guidance for wound infiltration. Pharmacotherapy. 2021 Aug;41(8):644-8. [PubMed] [Google Scholar]

7. Hobart-Porter N, Stein M, Toh N, Amega N, Nguyen HB, Linakis J. Safety and efficacy of rabies immunoglobulin in pediatric patients with suspected exposure. Hum Vaccin Immunother. $2021 \mathrm{Jul}$ 3;17(7):2090-6. [PubMed] [Google Scholar]

8. National Centre for Disease Control [Internet]. National Guidelines for Rabies Prophylaxis; 2019 [cited 2021 Sep 2]. Available from: https:// ncdc.gov.in/WriteReadData/linkimages / NationalGuidelinesforRabiesprophylaxis2019.pdf

9. John D, Royal A, Bharti O. Burden of illness of dogmediated rabies in India: a systematic review. Clin Epidem Global Health. 2021;12:100804. [Google Scholar]

10. Meyerhoff P, Manekeller S, Saleh N, Boesecke C, Schlabe $\mathrm{S}$, Wasmuth JC, van Bremen K, Eis-Hübinger AM, von Fischer-Treuenfeld J, Menting T, Rockstroh JK, SchwarzeZander C. Rabies post-exposure prophylaxis in Germany - What are the challenges? Epidemiol Infect. 2021 Mar 18;149:e119. [PubMed] [Google Scholar]

11. Wilde H. Failures of post-exposure rabies prophylaxis. Vaccine. 2007;25:7605-9. [PubMed] [Google Scholar]

12. Wilde $H$, Sirikawin $S$, Sabcharoen A, Kingnate $D$, Tantawichien T, Harischandra PA, Chaiyabutr N, de Silva DG, Fernando L, Liyanage JB, Sitprija V. Failure of postexposure treatment of rabies in children. Clin Infect Dis. 1996 Feb;22(2):228-32. [PubMed] [Google Scholar]

13. Chomchay $P$, Khawplod $P$, Wilde $H$. Neutralizing antibodies to rabies following injection of rabies immune globulin into gluteal fat or deltoid muscle. J Travel Med. 2000;7(4):187-8. [PubMed] [Google Scholar]

14. Rasooli A, Pourhossein B, Bashar R, Shirzadi MR, Amiri B, Kheiri EV, Mostafazadeh B, Fazeli M. Investigating possible etiologies of Post-Exposure Prophylaxis Failure and deaths from rabies infection: Case Reports. Int J
Med Toxicol Forensic Med. 2020;10(3):27378. [Google Scholar]

15. Suijkerbuijk AW, Mangen MJ, Haverkate MR, Luppino FS, Bantjes SE, Visser LG, Swaan CM, Ruijs WL, Over EA. Rabies vaccination strategies in the Netherlands in 2018: a cost evaluation. Euro Surveill. 2020 Sep;25(38):1900716. [PubMed] [Google Scholar]

16. Worathitianan $B$, Chockchalermwong $S$, Reongkhumklan S. Economic impact of revised rabies immunoglobulin administration protocol 2018 in the Emergency Department, Nakhon Pathom Hospital. Dis Control J [Internet]. 2019 Sep 30 [cited 2021 Oct 2];45(3):29304. Available from: https://he01.tci-thaijo.org/index. php/DCJ/article/view/174399

17. Sudarshan MK, Ashwath Narayana DH, Jayakrishnappa MB. Market mapping and landscape analysis of human rabies biologicals in India. Indian J Public Health. 2019 Sep;63(Supplement):S37-S43. [PubMed] [Google Scholar]

18. Sreenivasan N, Li A, Shiferaw M, Tran CH, Wallace R, Blanton J, Knopf L, Abela-Ridder B, Hyde T; Working group on Rabies PEP logistics. Overview of rabies post-exposure prophylaxis access, procurement and distribution in selected countries in Asia and Africa, 2017-2018. Vaccine. 2019 Oct 3;37 Suppl 1:A6-A13. [PubMed] [Google Scholar]

19. Wu W, Liu S, Yu P, Tao X, Lu X, Yan J, Wang Q, Zhang Z, Zhu $W$. Role of systemic injection of rabies immunoglobulin in rabies vaccination. Arch Virol. 2017;162:1701-3. [PubMed] [Google Scholar]

20. Bharti OK, Madhusudana SN, Wilde H. Injecting rabies immunoglobulin (RIG) into wounds only: a significant saving of lives and costly RIG. Hum Vaccin Immunother. 2017;13(4):762-5. [PubMed] [Google Scholar]

21. Bharti OK, Sharma UK, Kumar A, Phull A. Exploring the feasibility of a new low cost intra-dermal pre \& post exposure rabies prophylaxis protocol in domestic bovine in Jawali Veterinary Hospital, District Kangra, Himachal Pradesh, India. World J Vaccines. 2018;8:820. [Google Scholar]

22. Fekadu M, Shaddock JH, Baer GM. Excretion of rabies virus in the saliva of dogs. J Infect Dis. 1982;145:715-9. [PubMed] [Google Scholar]

23. Vaughn JB Jr, Gerhardt P, Newell KW. Excretion of street rabies virus in the saliva of dogs. JAMA. 1965;193:3638. [PubMed] [Google Scholar]

24. Madhusudana SN, Ashwin BY, Sudarsahan S. Feasibility of reducing rabies immunoglobulin dosage for passive immunization against rabies; results of in vitro and in vivo studies. Hum Vaccin Immunother. 2013;9:1914-7. [PubMed] [Google Scholar]

25. SAGE Working Group on Rabies vaccines and immunoglobulins and the World Health Organization 
(WHO) Secretariat [Internet]. Background paper; Proposed revision of the policy on rabies vaccines and rabies immunoglobulins; 2017 Sep 22 [cited 2021 May 4]. Available from: https://www.who.int/immunization/ sage/meetings/2017/october/1_Background_paper_ WG_RABIES_final.pdf

26. Bharti OK, Thakur B, Rao R. Wound-only injection of rabies immunoglobulin (RIG) saves lives and costs less than a dollar per patient by "pooling strategy". Vaccine. 2019 Oct 3;37 Suppl 1:A128-A131. [PubMed] [Google Scholar]

27. World Health Organization [Internet]. Weekly Epidemiological Record; No 16, 2018 [cited 2021 May 4];93:201-20. Available from: http://apps.who.int/iris/ bitstream/handle/10665/272371/WER9316.pdf?ua=1

28. Zhu Z, Huang $S$, Lu $S$, Zhang $M$, Meng $S$, Hu $Q$, Fang Y. Severe multiple rabid dog bite injuries in a child in central China: continuous 10-year observation and analysis on this case. Hum Vaccin Immunother. 2020;16(4):904-6. [PubMed] [Google Scholar]

29. Saesow N, Chaiwatanarat T, Mitmoonpitak C, Wilde H. Diffusion and fate of intramuscularly injected human rabies immune globulin. Acta Trop. 2000;76(3):289-92. [PubMed] [Google Scholar]

30. Quiambao BP, Ambas C, Diego S, Castells VB, korejwo J, Petit C, Rasuli A, Houillon G. Single visit, 4-site intradermal (ID) rabies vaccination induces robust immune responses 5 years after 1-week, 4-site ID primary post-exposure prophylaxis in the Phillipines. Vaccine. 2020 May;38(21):3740-6. [PubMed] [Google Scholar]

31. Lang J, Simanjuntak GH, Soerjosembodo S, Koesharyono C. Suppressant effect of human or equine rabies immunoglobulins on the immunogenicity of postexposure rabies vaccination under the 2-1-1 regimen: a field trial in Indonesia. MAS054 Clinical Investigator Group. Bull World Health Organ. 1998;76(5):491-5. [PubMed] [Google Scholar]

32. Bharti OK, Chand R, Chauhan A, Rao R, Sharma H, Phull A. "Scratches/Abrasions without bleeding" cause rabies: A 7 years rabies death review from medical college Shimla, Himachal Pradesh, India. Indian J Community Med. 2017;42:248-9. [PubMed] [Google Scholar] 